\title{
EXPLOITING SENTINEL-1 AMPLITUDE DATA FOR GLACIER SURFACE VELOCITY FIELD MEASUREMENTS: FEASIBILITY DEMONSTRATION ON BALTORO GLACIER
}

\author{
A. Nascetti ${ }^{\mathrm{a} *}$, F. Nocchi ${ }^{\mathrm{a}}$, A. Camplani ${ }^{\mathrm{a}}$, C. Di Rico ${ }^{\mathrm{a}}$, M. Crespi ${ }^{\mathrm{a}}$ \\ ${ }^{a}$ Geodesy and Geomatics Division, University of Rome La Sapienza, Italy (andrea.nascetti, mattia.crespi)@uniroma1.it
}

\author{
Commission VII, ThS 3 - Sentinel-I Radar
}

KEY WORDS: Sentinel-1, glacier monitoring, SAR amplitude tracking, surface velocity, Baltoro Glacier

\begin{abstract}
:
The leading idea of this work is to continuously retrieve glaciers surface velocity through SAR imagery, in particular using the amplitude data from the new ESA satellite sensor Sentinel-1 imagery. These imagery key aspects are the free access policy, the very short revisit time (down to 6 days with the launch of the Sentinel-1B satellite) and the high amplitude resolution (up to $5 \mathrm{~m}$ ). In order to verify the reliability of the proposed approach, a first experiment has been performed using Sentinel-1 imagery acquired over the Karakoram mountain range (North Pakistan) and Baltoro and other three glaciers have been investigated. During this study, a stack of 11 images acquired in the period from October 2014 to September 2015 has been used in order to investigate the potentialities of the Sentinel-1 SAR sensor to retrieve the glacier surface velocity every month. The aim of this test was to measure the glacier surface velocity between each subsequent pair, in order to produce a time series of the surface velocity fields along the investigated period. The necessary coregistration procedure between the images has been performed and subsequently the glaciers areas have been sampled using a regular grid with a $250 \times 250$ meters posting. Finally the surface velocity field has been estimated, for each image pair, using a template matching procedure, and an outlier filtering procedure based on the signal to noise ratio values has been applied, in order to exclude from the analysis unreliable points. The achieved velocity values range from 10 to 25 meters/month and they are coherent to those obtained in previous studies carried out on the same glaciers and the results highlight that it is possible to have a continuous update of the glacier surface velocity field through free Sentinel-1 imagery, that could be very useful to investigate the seasonal effects on the glaciers fluid-dynamics.
\end{abstract}

\section{INTRODUCTION}

The glaciers are a natural global resource and one of the principal climate change indicator at global and local scale, being influenced by temperature and snow precipitation changes; moreover the glaciers are the largest freshwater reservoirs on the Earth (Heid, 2011). Starting from 1894, thanks to the foundation of the International Glacier Commission at the 6th International Geological Congress in Zurich, several investigations have been carried out to study the complex glaciers dynamics. Nowadays, the World Glacier Monitoring Service (WGMS http://www.wgms.ch) in collaboration with the Global Land Ice Measurements from Space (GLIMS http://www.glims.org), collects observations on time changes in mass, volume, area and length of glaciers (glacier fluctuations), as well as statistical information about the perennial ice distribution (glacier inventories) (Zemp et al., 2008) (GLIMS, 2012). Among the parameters used for glacier monitoring, the glaciers surface velocity is an important element, since it influences the events connected to glaciers changes (mass balance, hydro balance, glaciers stability, landscape erosion) (Heid, 2011) (Karpilo, 2009) (Rolstad and Norland, 2009). In detail the glacier surface velocity is:

- connected to the glaciers mass balance, since it is useful in order to compute the flow rate that reaches the ablation area (Heid, 2011) (Karpilo, 2009) (Pelto et al., 2008)

- a stability indicator, since it measures the rate at which a glacier is sliding (calving rates) (Heid, 2011) (Rolstad and Norland, 2009)

- important for tracking material transportation and erosion phenomena (Heid, 2011) (Kääb, 2005)

\footnotetext{
${ }^{*}$ Corresponding author
}

In particular, the surface glacier velocity can be measured using both in-situ survey and remote sensing geomatic techniques. Although the in-situ surveys are accurate and have the advantage of allowing ice flow monitoring at a high temporal resolution, it is difficult to cover wide and not accessible areas; moreover GPS surveys could be expensive and does not allow the acquisition of enough points to investigate the complex ice-dynamics (Karpilo, 2009). On the other hand, both optical and SAR satellite imagery enable the continuous monitoring of wide areas of the Earth surface and provide information independent from logistic constraints.

Concerning optical satellite data, glaciers horizontal displacements have been measured mostly from repeated Landsat or ASTER data using different image correlation techniques devoted to estimate the pixel offsets. For such work, the spatial resolution of the used images is the most crucial parameter, besides the time period between the acquisitions. Well-defined surface features, such as large crevasses or local debris cover, have to be identified at the available resolution (Kääb et al., 2003). In this respect, for example, GLIMS database includes glaciers surface velocity fields computed using LANDSAT 7 and ASTER imagery (both with ground resolution of $15 \mathrm{~m}$ ) (Gourlet et al., 2016); the main drawbacks are the low accuracy and temporal resolution of the glacier surface velocity, limited by the low GSD (Ground Sample Distance) and high revisit time of these sensors, and the dependence on the illumination and weather conditions.

Up to now, two main approaches have been used for the estimation of glaciers surface velocities exploiting the two information available on SAR data: the phase based SAR interferometry (InSAR) and the amplitude based offset-tracking techniques (Joughin et al., 2010). Most of the previous studies has been conducted using the ENVISAT satellite. The mission was launched 
on 1 March 2002 and ended on 8 April 2012 and the Sun synchronous polar orbit satellite carried a SAR sensor that operated at $\mathrm{C}$ band and able to collect repeat-pass imagery with a reviset time of 35 days. The potential of InSAR to map displacements with centimetric resolution has been succeffuly applied obtaining interesting results in glaciology (Erten et al., 2009) (Evans, 2000). However, in the case of phase decorrelation due to rapid and incoherent glacier flow, offset-tracking technique outperfom the InSAR one becoming a welcome alternative for the estimation of glacier motion (Hollands, 2012) (Riveros et al., 2013)

\section{SENTINEL-1 FOR GLACIAR MONITORING}

Sentinel-1 is a costellation of two satellites that carry SAR sensor, known as Sentinel 1-A and Sentinel 1-B. Sentinel-1A was launched on 3 April 2014 and Sentinel-1B will be launched on 22 April 2016. This mission is able to acquire images with $\mathrm{C}$ band SAR sensor both day and night, independently from weather conditions. Sentinel-1A orbits at an altitude of about $700 \mathrm{~km}$ and it has a reviset time of 12 days that will be halved after the launch of Sentinel-1B. The orbit is sun-syncronous near polar. Sentinel-1 is used in the Copernicus Programme, a framework coordinated by European Commission for monitoring of the Earth. ESA is responsible for developing the family of Sentinel satellites and it permits data free automatic download of the areas of interest from the ESA portal to all users. The data acquired by Sentinel- 1 are divided in three different levels of elaboration; in particular in the level 1 there are two types of product known as GRD (Ground Range Detected) and SLC (Single Look Complex). The GRD images include only the amplitude information, whereas the SLC images both amplitude and phase information.

The aim of this preliminary work is to investigate the potential of the new Sentinel-1A free SAR data for monitoring the glaciers surface velocity and highlight the seasonal fluctuations of the velocity field. In particular the key aspects that Sentinel-1 images present and that can represent an advancement for these kind of studies are the free access policy, the very short revisit time (down to 6 days with the incoming launch of the Sentinel-1B satellite) and the high amplitude resolution (up to $5 \mathrm{~m}$ ); these characteristics could offer a more detailed surface velocity measurement in term of both spatial and temporal resolution, potentially all over the world.

\section{METHOD AND DATA}

The main steps that has been performed to extract the glaciar surface velocities field starting from the Sentinel 1-A SAR amplitude information are briefly resumed as follow:

- images stack acquisition and co-registration

- glacier area definition and sampling

- glacier surface velocity computation using the so called offset tracking

\subsection{Images stack acquisition and co-registration}

During this work several tests have been conducted in order to select the optimal temporal resolution of the images stack. It is clear that the optimal time interval between the two subsequently images is related to the expected surface velocity values, also considering the image ground resolution. The best results have been obtained using a temporal resolution of 24/36 days (respectively two or three times the Sentinel 1-A revisiting time). As a matter of fact, no significant results are obtained if the displacement of the glacier surface is smaller than the ground resolution in the chosen temporal resolution; on the contrary with lower temporal resolution the speckle decorrelation increases quickly between the images pair.

After the selection of the stack it is necessary to perform the coregistration process in order to align, with a subpixel accuracy, all the imagery. We have performed tests using several commercial and open source software: the open source GMTSAR processor; the Sentinel-1 Toolbox (S1TBX) developed by ESA and the commercial SARscape developed by sarmap sa. Despite the SAR coregistration process is consolidated for most of the high-resolution SAR sensors we found some technical issues in Sentinel-1 stack data management. The best results in term of coregistration accuracy have been obtained using the SARscape software.

\subsection{Glacier area definition and sampling}

The GLIMS worldwide database provides the glacier outlines in standard shapefile format in WGS84 reference system (GLIMS, 2012). Starting from the glacier outlines we have sampled the area with a regular grid with a $250 \times 250$ meters posting obtaining a set of $2 \mathrm{D}$ points. For each of these points we have computed its height using the SRTM v4 (Shuttle Radar Topographic Mission) global digital surface model. Subsequently we have reprojected the 3D points in the SAR image geometry using the slant-range model (Capaldo et al., 2011) obtaining a set of image points where the glacier surface velocities were computed as described hereafter.

\subsection{Surface velocity computation}

Surface velocities were derived using offset intensity tracking algorithms on repeat SAR satellite imagery, also known as a template matching procedure (Capaldo et al., 2014) (Joughin et al., 2010). Based on the image intensity, this kind of techniques track surface features and also speckle pattern on a pair of coregistered images acquired in two different epochs. Even in SAR image pairs characterize by low coherence, distinct features (e.g. crevasses) can still be tracked using the same methods as applied to optical imagery (Luckman et al., 2003).

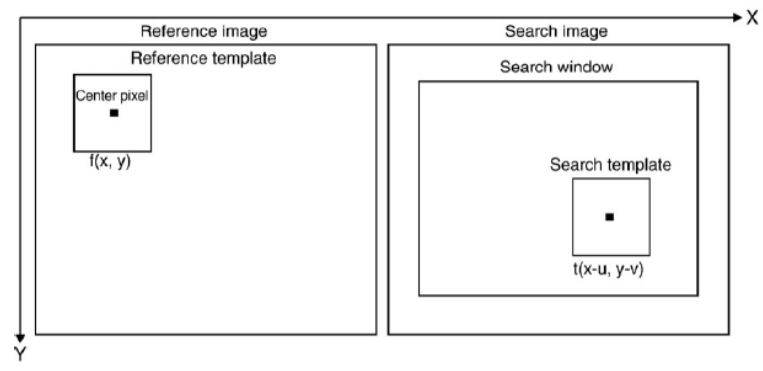

Figure 1: Offset tracking

In this work the glacier displacements between two consecutive epochs were estimated by the software CIAS developed at the Department of Geosciences, University of Oslo (A. Kääb and Vollmer, 2000) (Heid and K0€10Ł1b, 2012). This software is based on the NCC (Normalized Cross Correlation) algorithm for evaluating the similarity between two images. This method consists to identify surface features across two images acquired at different epochs. Firstly, we have to consider a pixel $p$ that has 
the coordinates $(\mathrm{x}, \mathrm{y})$ in the first image; this pixel will become the focal point of the block reference size $\mathrm{NxN}$. In the second image, the system creates a search window with size MxM that is the area where the search template have to find the equivalent focal point $\mathrm{p}$. For doing that, the system calculate the NCC index on the different pixels and it chooses the pixel with the highest value (Figure1).

Finally an outlier filtering procedure based on the signal to noise ratio (SNR) values has been applied in order to remove from the analysis unreliable points.

\section{RESULTS}

We applied this method to several glaciers, starting from Baltoro,located in the Karakoram mountain range, Kashmir region (North Pakistan) in order to highlight the advantages and the drawbacks of computing surface velocity using Sentinel-1 data. The Karakoram is part of the Hindu Kush-Karakoram-Himalaya mountain range. It is located between the borders of India, Pakistan, Afghanistan, and China and stretches over $500 \mathrm{~km}$ in a NW to SE direction (see Fig. 2). In detail we have analysed the following four glaciers, that are the most famous and characteristic of the area:

- Baltoro glacier: it is one of the biggest glaciers in the world; it is located in Pakistan and runs trought part of the Karakoram range. It is $63 \mathrm{~km}$ at lenght and its surface is about 700 $\mathrm{kmq}$. Baltoro glacier is near some of the most highest peaks of the world as K2, Gasherbrum and Masherbrum. It is originated by the confluence of different tributary glaciers; the most important of them are Godwin Austen glacier, Abruzzi glacier and Broad Peak glacier

- Biafo glacier: this glacier is located near Baltoro glacier. It is the second longest of the Karakoram glaciers at $68 \mathrm{~km}$. Its basin covers a total area of $853 \mathrm{kmq}, 628 \mathrm{kmq}$ of which are permanent snow and ice, with 68 per cent of the glacier area forming the accumulation zone. Biafo Glacier differs from most of the other Karakoram glaciers, including Baltoro glacier, in being nourished mainly by direct snowfall rather than by avalanching; for that characteristic, the glacier surface is covered by snow and appears uniform

- Hispar glacier: this is a $49 \mathrm{~km}$ long glacier, which meets the Biafo Glacier at the Hispar La (Pass) at an altitude of $5,128 \mathrm{~m}$ to create the worlds longest glacial system outside of the polar regions.

- Chogo glacier: it is a $47 \mathrm{~km}$ long glacier and it is nourished mainly by avalanches and so its surface is debris-covered. For that reason it is very similar to Baltoro glacier, even if it is smaller.

To estimate the surface velocity of those glaciers, we downloaded from the Sentinel scientific data hub (https://scihub.copernicus.eu/) 11 SAR Sentinel 1-A images (see Figure3) in ground range format (GRD) with a spatial resolution of $10 \times 10 \mathrm{~m}$. SAR images were revealed with Interferometric Wide Swath Mode and have an azimuth width of $250 \mathrm{~km}$.

\subsection{Baltoro Glacier}

For each couple of images available in the stack (Figure3) we computed the glacier surface velocity field. In the Fig. 4 we display the flow of glacier surface velocity expressed in $\mathrm{m} / \mathrm{months}$ obtained about every two months. The six figures highlight the natural downward movement of the Baltoro Glacier: on the upper area the surface velocities are relatively high while at the terminus are generally lower. In the central part we obtained that it is about $100 \mathrm{~m} / \mathrm{yr}$. Moreover it is clearly visible that the glacier margins are essentially stationary compared with the center due to the ice friction against the surrounding rocks. In particular over some of the blue areas it has been not possible to retrieve the velocity values because these areas are affected by SAR geometric distortion (i.e. layover and foreshortening). Figure 4 (c) shows a wrong coregistration between the two corresponding images: there is an evident rotation that compromise the surface velocity measurements (the margins of glacier have a velocity much higher than the expected values).

The velocity has some reasonable variations during the whole considered period: in the warmer seasons it increases, whereas during the winter it reduces. This phenomenon is more evident in the Figure.4 (f), where we can see some values of velocity higher along the glacier central axis. Moreover we compared our results with the one obtained by the Institute of Geodesy and Geophysics, University of Chinese Academy of Sciences. In this study they used ENVISAT ASAR three images acquired during the period 2004-2006 and evaluated the surface velocity field using the offset tracking method (Sun et al., 2014). The results have shown that the velocities were high in the upper area, while they were lower towards glacier terminus and the margins. The highest velocities reached $160 \mathrm{~m} / \mathrm{yr}$, while close to the terminus they were under $10 \mathrm{~m} / \mathrm{yr}$. This study is in accordance with our results though it was not able to highlightt he seasonal variation of the surface velocity.

\subsection{Chogo - Lugma Glacier}

The results we obtained are close to those concerning Baltoro glacier in the sense that the method is able to give a good estimation of the surface velocity field. The surface velocities values (about $15-20 \mathrm{~m} / \mathrm{month}$ ) are, on average, higher than those obtained for the Baltoro glacier. This difference has also been reported in the past by some studies that have been involved in mapping the trend of surface velocity of the Karakoram glaciers (Rankl et al., 2014). Also in the Figure5 (c) there are evident problems of coregistration between the two images, as well as in the corresponding graph obtained for Baltoro glacier.

\subsection{Biafo and Hispar Glaciers}

We tried to estimate also the surface velocity field of both $\mathrm{Bi}$ afo and Hispar glaciers. Biafo glacier is different from the other glaciers in this region because, as mentioned, it is mainly nourished by direct snow-fall instead of avalanching; for this specificity its surface is not debris covered-apart from the final sectionand looks like very uniform. For that reason the obtained results are worse than those concerning both Baltoro and Chogo-Lugma glacier. In the Figure6, it is evident that the results obtained on the Biafo Glacier are not physically based (see the red vectors), whereas those on a part of the Hispar surface are physically admissible (see the yellow vectors). Given the ambiguity of those results, we decided that it was pointless to offer considerations about the velocity. The lack of physically based results on the Biafo glacier surface may be explained just by the fact that Biafo surface glacier is uniformly covered by snow during all the seasons; for that reason the speckle texture is too uniform and off-tracking method is not able to give robust results. On the contrary, the surface of the final part of Hispar glacier is less uniform than that of Biafo glacier (see the yellow vectors) and it is possible to obtain good results. 


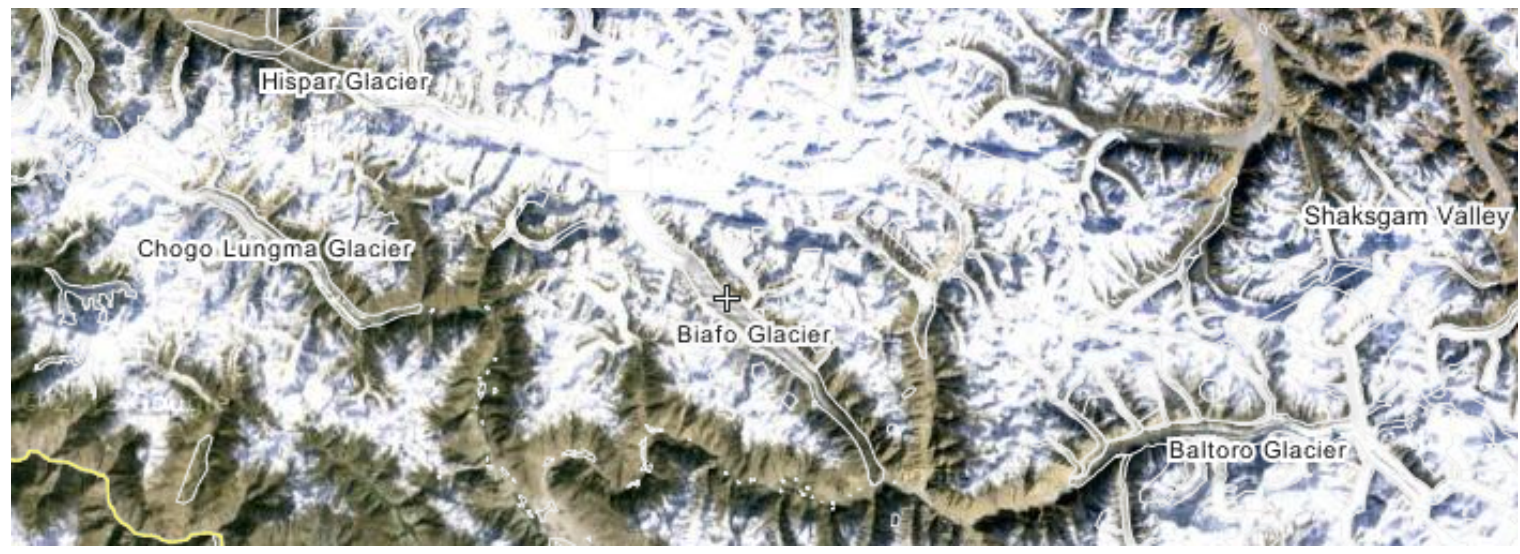

Figure 2: Karakoram, Kashmir region, North Pakistan

\begin{abstract}
IJ S1A_IW_GRDH_1SSV_20141008T005749_20141008T005818_002731_0030FE_1F65.SAFE 1] S1A_IW_GRDH_1SSV_20141113T005747_20141113T005816_003256_003C3D_2D1E.SAFE DIS S1A_IW_GRDH_1SSV_20141219T005748_20141219T005817_003781_004839_6533.SAFE D. S1A_IW_GRDH_1SSV_20150112T005747_20150112T005816_004131_00501B_4383.SAFE 1. S1A_IW_GRDH_1SSV_20150217T005745_20150217T005814_004656_005BF3_D917.SAFE 13 S1A_IW_GRDH_1SSV_20150325T005745_20150325T005814_005181_006898_D4D1.SAFE 1. S1A_IW_GRDH_1SSV_20150430T005749_20150430T005817_005706_007537_C07D.SAFE D. S1A_IW_GRDH_1SSV_20150605T005749_20150605T005818_006231_00824B_30C7.SAFE D. S1A_IW_GRDH_1SSV_20150711T005757_20150711T005825_006756_009103_3CF6.SAFE D. S1A_IW_GRDH_1SSV_20150816T005752_20150816T005821_007281_009FB3_D979.SAFE D. S1A_IW_GRDH_1SSV_20150909T005753_20150909T005822_007631_00A93B_0EDB.SAFE
\end{abstract}

Figure 3: Dataset

\section{CONCLUSIONS AND FUTURE PROSPECTS}

The aim of this work was to investigate the Sentinel-1 SAR imagery potential to periodically retrieve glaciers surface velocity, also highlighting the seasonal fluctuation. In order to verify the reliability of the proposed approach, a first experiment has been performed using a stack of 11 images acquired in the period from October 2014 to September 2015 over the Karakoram mountain range (North Pakistan). The aim of this test was to evaluate the glacier surface velocity between each subsequent pair, in order to produce a time series of the surface velocity fields along the investigated period.

The necessary co-registration procedure between the images has been performed using the SARscape software and subsequently the glaciers areas, identified by the outlines available on the GLIMS database, have been sampled using a regular grid with a posting of $250 \mathrm{~m}$. Finally the velocity has been measured, for each image pair, using the template matching procedure implemented in the CIAS software; subsequently an outlier filtering procedure based on the signal to noise ratio values has been applied, in order to exclude from the analysis unreliable points.

Four different glaciers has been investigated: as regard the Baltoro and Chogo-Lugma glaciers, the achieved surface velocity values on the central axis range from 10 to 25 meters/month and they are coherent to those obtained in previous studies. Some difficulties has been encountered to coregistered the images acquired during the period range from January to March compromising the corresponding results. Contrary of Baltoro and ChogoLugma, the Biafo and Hispar glaciers are uniformly covered by snow during all the seasons, and it has been not possible to correctly retrieve the surface velocity field due to the lack of speckle texture. In the next test we will investigated the integration of the offset tracking with the InSAR technique using the Sentinel-1 data. Moreover, in the future to improve the outlier rejection will be considered the usage of Digital Surface Model (DSM) of the glacier to compute the local slope values and filter out the surface velocities that are significantly disagree with the morphology.

Overall, the results presented in this work confirm that SAR offset tracking is an effective method to obtain glacier surface velocity and highlight that it is possible to have a continuous update of the glacier surface velocity field through Sentinel-1 imagery, that could be very useful to investigate the seasonal effects on the glacier fluid-dynamics. It is important to underline that Sentinel1 mission made free available high resolution $(5 \mathrm{~m})$ SAR data with a worldwide coverage, enabling the possibility to establish a global web monitoring service to routinely and continuous update glacier surface velocity.

\section{ACKNOWLEDGEMENTS}

We are indebted with P. Pasquali and A. Meroni for making the ENVI-SARscape software available for this work.

\section{REFERENCES}

A. Kääb, A. and Vollmer, M., 2000. Surface geometry, thickness changes and flow fields on creeping mountain permafrost: Automatic extraction by digital image analysis. Permafrost and Periglacial Processes 11(4), pp. 315-326.

Capaldo, P., Crespi, M., Fratarcangeli, F., Nascetti, A. and Pieralice, F., 2011. High-resolution sar radargrammetry: A first application with cosmo-skymed spotlight imagery. IEEE Geoscience and Remote Sensing Letters 8(6), pp. 1100-1104.

Capaldo, P., Fratarcangeli, F., Nascetti, A., Mazzoni, A., Porfiri, M. and Crespi, M., 2014. Centimeter range measurement using amplitude data of terrasar-x imagery. ISPRS - International Archives of the Photogrammetry, Remote Sensing and Spatial Information Sciences XL-7, pp. 55-61.

Erten, E., Reigber, A., Hellwich, O. and Prats, P., 2009. Glacier velocity monitoring by maximum likelihood texture tracking. IEEE Transactions on Geoscience and Remote Sensing 47(2), pp. 394-405.

Evans, A. N., 2000. Glacier surface motion computation from digital image sequences. IEEE Transactions on Geoscience and Remote Sensing 38(2), pp. 1064-1072.

GLIMS, 2012. Glims, and national snow and ice data center. 2005, updated 2012. GLIMS Glacier Database, Version 1. Boulder, Colorado USA. NSIDC: National Snow and Ice Data Center. 


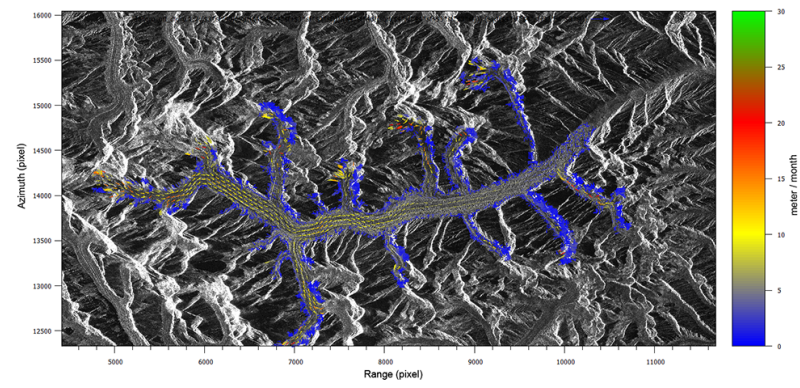

(a) 8th October 2014 - 19th December 2014

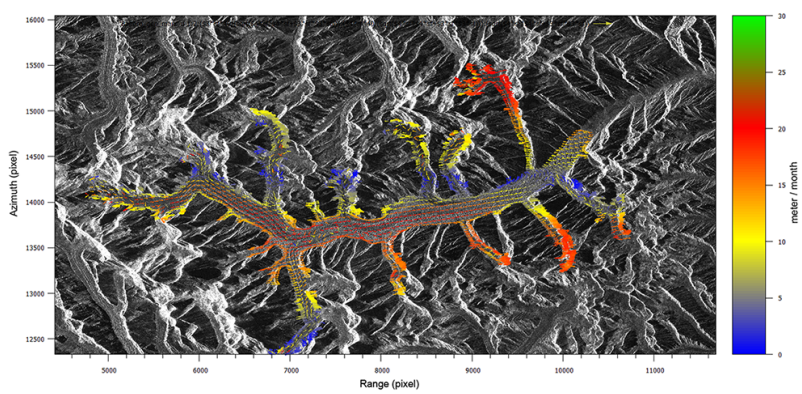

(c) 12th January 2015 - 25th March 2015

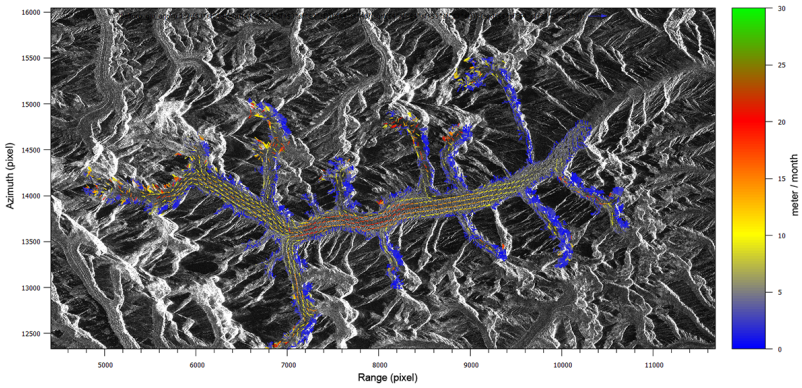

(e) 5th June 2015 - 16th August

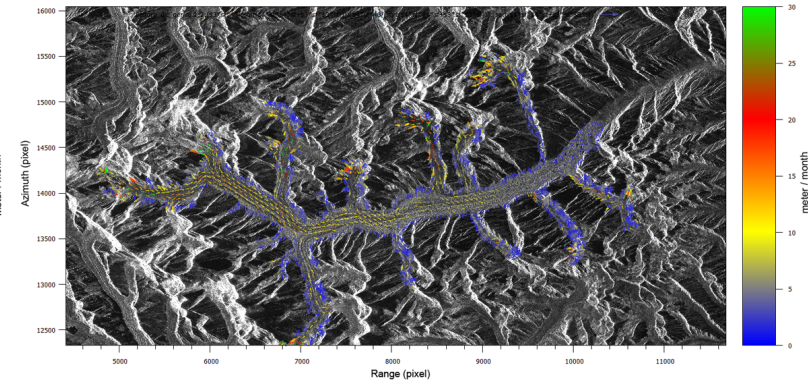

(b) 19th December 2014 - 12th January 2015

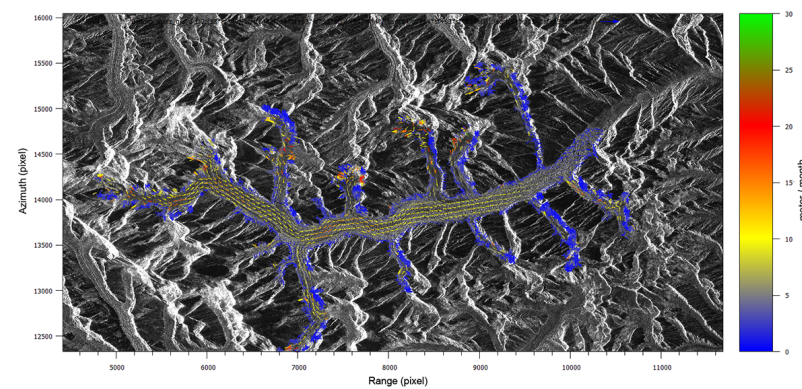

(d) 25th March 2015 - 5th June 2015

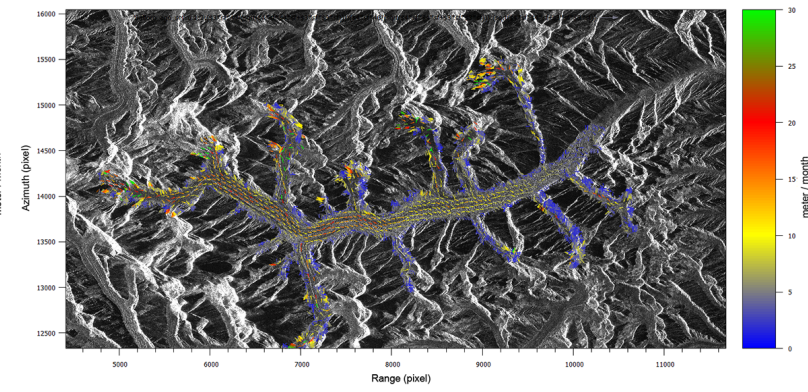

(f) 16th August 2015 - 9th September 2015

Figure 4: Temporal series of Baltoro Glacier surface velocity field in slant-range geometry

Gourlet, P., Rignot, E., Rivera, A. and Casassa, G., 2016. Ice thickness of the northern half of the patagonia icefields of south america from high-resolution airborne gravity surveys. Geophysical Research Letters 43(1), pp. 241-249. 2015GL066728.

Heid, T., 2011. Deriving glacier surface velocities from repeat optical images. PhD Thesis, University of Oslo.

Heid, T. and K0€10€1b, A., 2012. Evaluation of existing image matching methods for deriving glacier surface displacements globally from optical satellite imagery. Remote Sensing of Environment 118, pp. $339-355$.

Hollands, T., 2012. Motion tracking of sea ice with sar satellite data. PhD Thesis, University of Bremen.

Joughin, I., Smith, B. E. and Abdalati, W., 2010. Glaciological advances made with interferometric synthetic aperture radar. Journal of Glaciology, Volume 56, Number 200, December 2010, pp. 1026-1042(17).

Kääb, A., 2005. Combination of SRTM3 and repeat ASTER data for deriving alpine glacier flow velocities in the bhutan himalaya. Remote Sensing of Environment 94(4), pp. 463 - 474.
Kääb, A., Huggel, C., Paul, F., Wessels, R., Raup, B., Kieffer, H. and Kargel, J., 2003. Glacier monitoring from aster imagery: Accuracy and applications. Proceedings of EARSeL-LISSIGWorkshop Observing our Cryosphere from Space, Bern, March 11 C 13, 2002. EARSeL e Proceedings. 2. 43-53.

Karpilo, R., 2009. Glacier monitoring techniques. Geological Society of America.

Luckman, A., Murray, T. and Jiskoot, 2003. Ers sar featuretracking measurement of outlet glacier velocities on a regional scale in east greenland. Annals of Glaciology 36(1), pp. 129134.

Pelto, M. S., Miller, M. M., Adema, G. W., Beedle, M. J., McGee, S. R., Sprenke, K. F. and Lang, M., 2008. The equilibrium flow and mass balance of the taku glacier, alaska 1950092006 . The Cryosphere 2(2), pp. 147-157.

Rankl, M., Kienholz, C. and Braun, M., 2014. Glacier changes in the karakoram region mapped by multimission satellite imagery. The Cryosphere 8(3), pp. 977-989. 


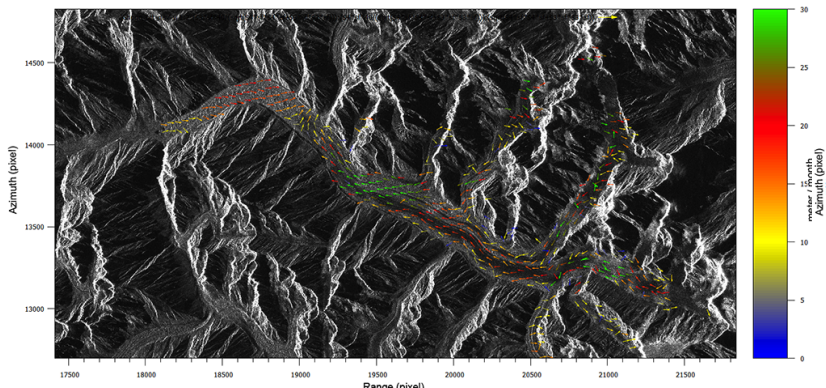

(a) 8th October 2014 - 19th December 2014

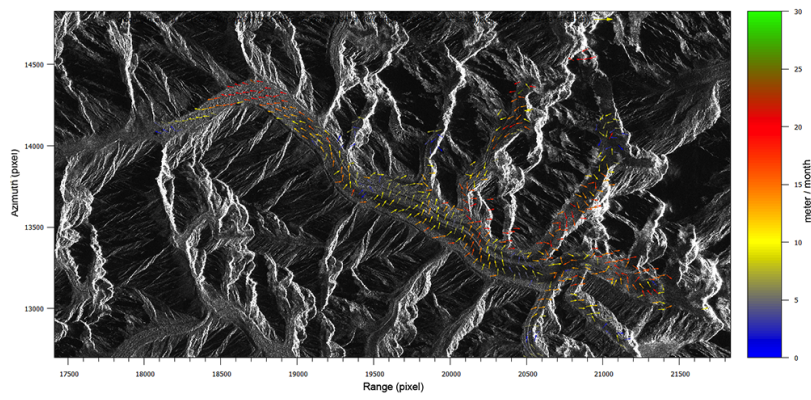

(c) 12th January 2014 - 25th March 2015

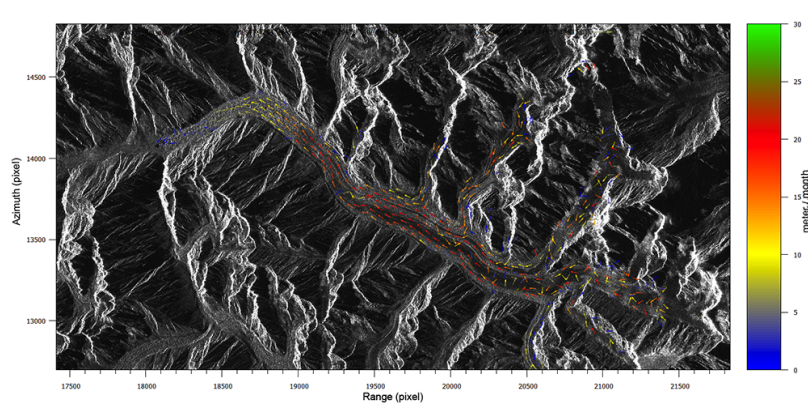

(e) 5th June 2015 - 16th August

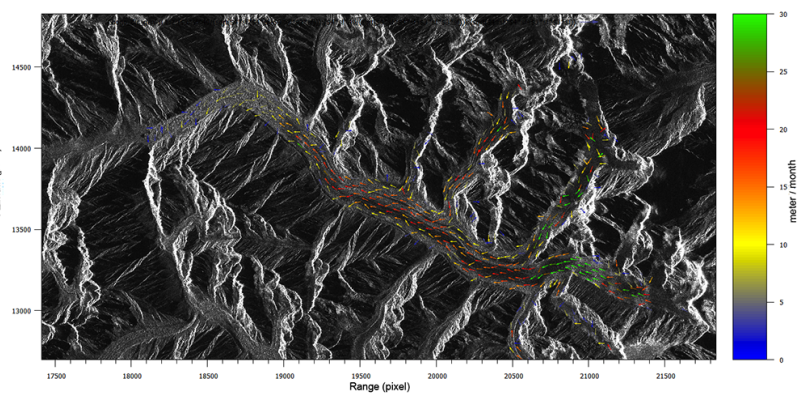

(b) 19th December 2014 - 12th January 2015

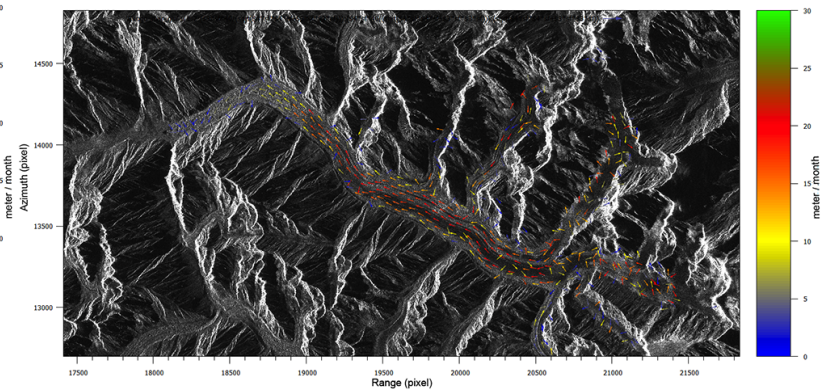

(d) 25th March 2015 - 5th June 2015

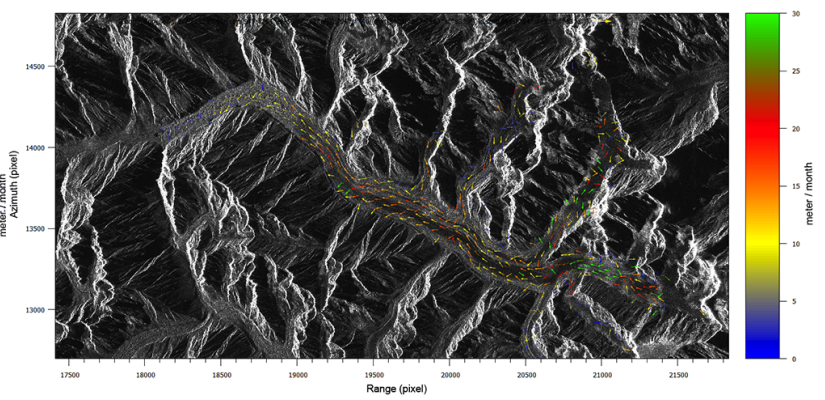

(f) 16th August 2015 - 9th September 2015

Figure 5: Temporal series of Chogo Glacier surface velocity field in slant-range geometry

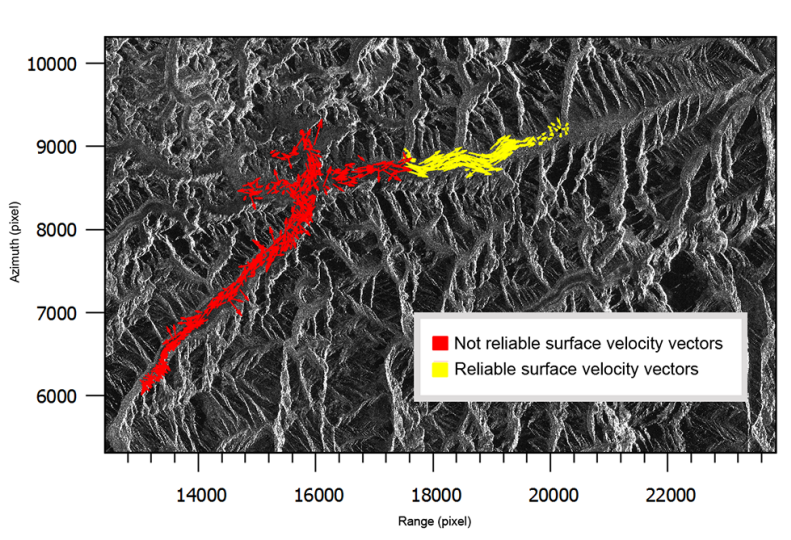

Figure 6: Experimental results of Biafo Glacier during the period of 8th october 2014 - 13th november 2014

Riveros, N., Euillades, L., Euillades, P., Moreiras, S. and Balbarani, S., 2013. Offset tracking procedure applied to high resolution sar data on viedma glacier, patagonian andes, argentina. Advances in Geosciences 35, pp. 7-13.
Rolstad, C. and Norland, R., 2009. Ground based interferometric radar for velocity and calving rate measurements of the tidewater glacier Kronebreen, Svalbard, from August 2007 and 2008. In: D. N. Arabelos and C. C. Tscherning (eds), EGU General Assembly Conference Abstracts, EGU General Assembly Conference Abstracts, Vol. 11, p. 2192.

Sun, Y., Jiang, L., Wang, H., Liu, L., Sun, Y. and Shen, Q., 2014. Detection and analysis of surface velocity over baltoro glacier with envisat asar data. In: 2014 IEEE Geoscience and Remote Sensing Symposium, pp. 4030-4033.

Zemp, M., Roer, I., Kääb, A., Hoelzle, M. and Paul, F., 2008. Global glacier changes: facts and figures. World Glacier Monitoring Service (WGMS) report. 